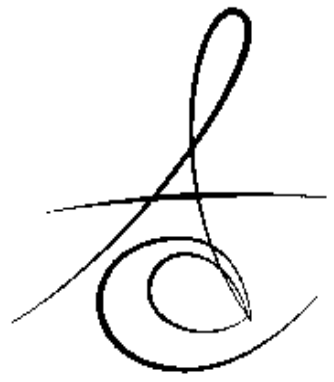

\title{
MANYETİK REZONANS GÖRÜNTÜLEMENİN DİŞ HEKİMLİĞİNDE KULLANIMI VE DENTAL MATERYALLERE ETKİLERİ
}

\section{MAGNETIC RESONANCE IMAGING IN DENTISTRY AND ITS EFFECT ON DENTAL MATERIALS}

\author{
Dr. Öğr. Üyesi Tahir KARAMAN * \\ Dr. Öğr. Üyesi Sedat GÜVEN**
}

Dr. Öğr. Üyesi Bekir EŞER *

Dr. Öğr. Üyesi Tuba TALO YILDIRIM***

\begin{abstract}
Makale Kodu/Article code: 2785
Makale Gönderilme tarihi: 12.04 .2016
\end{abstract}

Kabul Tarihi: 17.05.2016

öz

Radyolojik görüntüleme yöntemlerinden biri olan Manyetik Rezonans Görüntüleme, hastalıkların tanısına çok önemli katkıları bulunmasından dolayı yaygın bir şekilde medikal alanda kullanılmaktadır. Bu görüntüleme tekniğinde kuvvetli manyetik alan oluşması ve vücutta bulunan metalik objelerin bu manyetik alandan etkileşimleri hasta açısından potansiyel sağlık riskleri oluşturabilmektedir. Diş hekimliği alanında yaygın bir şekilde kullanılan Dental implantlar, Ortodontik braketler ve teller, Metal destekli sabit ve hareketli restorasyonlar vb. gibi içeriğinde metal bulunan objelerin varlığında Manyetik Rezonans Görüntülemesi esnasında oluşabilecek manyetik alan etkileşimlerinin yeterince bilinmesi gerekir. Görüntüleme esnasında hasta açısından oluşabilecek riskleri en asgari düzeye indirebilmek için vücutta bulunan ve manyetik alandan etkilenen metalik objeler ile ilgili gerekli tedbirlerin alınması gerekir.

Anahtar Kelimeler: Manyetik Rezonans Görüntüleme, dental alaşımlar, manyetik alan etkileşimi

\section{GİRİş}

Manyetik rezonans görüntüleme yöntemi(MRI) özellikle yumuşak dokuları ilgilendiren baş-boyun hastalıklarının tanısında hayati öneme sahip bir görüntüleme yöntemidir. Bu görüntüleme yönteminde yüksek çözünürlükte görüntüler elde edilmesinin yanında iyonize radyasyonun kullanılmaması yöntemin büyük avantajlarındandır. ${ }^{1,2}$ Baş ve boyun bölgesinde kullanılan bu yöntem başlıca temporomandibular eklem hastalıklarında, santral sinir sistemi ile ilgili hastalıklarda, beyin tümörlerinde, göz ve iç kulak hastalıklarında, boyun bölgesi tümörleri, kas sistemi ile ilgili hastalıklarda,

\section{ABSTRACT}

Magnetic resonance imaging (MRI) is one of the radiologic imaging techniques, using widely in medical field due to significant contribution to the diagnosis of diseases. Formation of the strong magnetic field and its interaction with metallic objects in the body may cause potential risks for patient. In the presence of metal containing objets in dentistry such as dental implants, orthodontic brackets and wires, metalsupported fixed and removable restorations, adequate information about the features of magnetic field and its interaction with the metallic objects should be known. To take necessary measures related with the magnetic field interactions, will reduced risk level during imaging.

Keywords: Magnetic Rezonance Imaging, dental alloys, magnetic field interactions

nörodejeneratif hastalıklarda, kemik veya eklem tümörlerinin, vasküler malformasyonların vb. gibi hastalıkların teşhisinde önemli bir rol oynamaktadır ${ }^{3-8}$.

\section{MRI tarihi ve metodu:}

Manyetik alan ile ilgili çalışmalar 18 . yy sonlarına doğru başlamıştır. Nikola Tesla, Sir Joseph Larmor, Walter Gerlach, Otto Stern, Isıdor Rabi Manyetik Rezonans Görüntüleme ile ilgili bilgilerin geliştirilmelerinde önemli katkıları olmuştur. Birbirlerinden bağımsız olarak çalışan Bloch ve Purcell 1946 yılında atom çekirdeklerinin enerji verilmesinden sonra manyetik alan oluşturduğu ve bu enerjinin tekrar emisyonundan sonra orijinal haline geldiği tanımlanmış ve bu

\footnotetext{
* Fırat Üniv. Diş Hek. Fak. Protetik Diş Ted. AD.

" Dicle Üniv. Diş Hek. Fak. Protetik Diş Ted. AD.

${ }^{* * *}$ Fırat Üniv. Diş Hek. Fak. Periodontoloji AD.
}

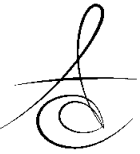


tanımlama ile Manyetik Rezonans tarif edilmiştir. Paul Lauterbur ve Peter Mansfield manyetik rezonans görüntüleme yöntemini 1974 yılında bağımsız olarak yayınlamıştır ve MR görüntüleme yöntemi olarak bilinen bu teknik 30 yıldan fazladır klinik olarak kullanılmaktadır. Fourier'in katı cisimlerin arasındaki ISı transferi analizi için geliştirdiği matematiksel dönüşüm yöntemi 1975 yılında Richard Ernst tarafından MR sinyal analizi ve görüntüleme rekonstrüksiyonunda kullanılmaya başlanmış olup bu teknik tüm modern MR görüntüleme tarayıcılarında kullanılmaktadır. MRI veya NMR (Nükleer Manyetik Rezonans) prensiplerinin geliştirilmesinde birçok bilim adamının katkısı olmuş ve bazı bilim adamlarına bu katkılarından dolayı Nobel bilim ödülü kazandırmıştır. ${ }^{9}$

Manyetik rezonans görüntülemenin temel prensibinde kuvvetli bir manyetik alan oluşturulması ve çekirdekte bulunan protonların titreşimleri(spin) ile ilgili alınan sinyallerin bilgisayar ortamında işlenerek görüntüler elde edilmesi esasına dayanır. ${ }^{10} \mathrm{Bu}$ spin sayesinde çevrelerinde doğal bir manyetik alan oluşur. ${ }^{10,11}$ Çekirdekteki bulunan nötron ve protonlar çift sayıda olduklarından ve birbirlerinin dönüş hareketlerini ortadan kaldırmalarından dolayı manyetik özellikleri yoktur. $\mathrm{Bu}$ nedenle tek proton ve nötrona sahip çekirdeklerde manyetik özellik vardır. Bu özellikler MR görüntüleme esasının temelini oluşturur ve Hidrojen atomunun tek protona sahip olması, güçlü manyetik özellik göstermesi ve vücut dokularında bulunması sebebiyle MR görüntülemede sinyal kaynağı olarak kullanılmaktadır. ${ }^{10}$

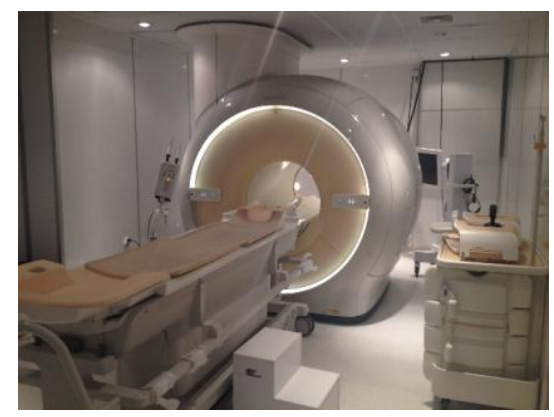

Şekil 1. Manyetik Rezonans Görüntüleme ünitesi

Manyetik alanın yoğunluğunu belirlemek için T (Tesla birimi kullanılır ve 1 Tesla yeryüzünün manyetik etkisinden 10.000 kez daha güçlüdür. Düşük manyetik alan kullanan 0.2-0.3 T, yüksek manyetik alan kullanan 1.5-3.0 T ve ultra yüksek manyetik alan kullanan 7.0-10 T manyetik alana sahip cihazlar medikal alanda ve araştırmalarda MR görüntüleme amacıyla kullanılmaktadır. $^{2}$

\section{Diş Hekimliğinde MR Görüntülemenin Kullanımı:}

MR görüntüleme diş hekimliğinde ana kullanım alanları başlıca yumuşak doku lezyonları, tükrük bezi hastalıkları, temporomandibular eklem ile ilgili sinovit, internal düzensizlikler(derangement) gibi rahatsızlıkları ve tümörleri, odontojenik kist ve tümörlerin ayrımında, ayrıca dil, yanak ve lenf nodlarının neoplazilerinin tanımlanmasında kullanılmaktadır. ${ }^{12,13}$ Bazı skuamoz cell karsinom olgularının görüntülemesi ise sadece MR görüntüleme ile sağlanmaktadır. ${ }^{12}$ Hastalıkların teşhis görüntülemelerinin yanında MR görüntüleme diş hekimliğinde çocuk ve yetişkinlerdeki gömülü dişlerin lokalizasyonların ve komşu yapılar ile ilişkilerinin değerlendirilmesi amacıyla, ${ }^{14}$ dental pulpa dokusu ile ilgili incelemelerde, ${ }^{15}$ diş ve kök kanal morfolojilerinin değerlendirilmesinde, ${ }^{16}$ protetik restorasyonların preparasyon bölgesinin sayısallaştırılıp, elde edilen dijital verilere göre restorasyonların üretilmesine yardım amacıyla da kullanılmaktadır. ${ }^{17}$

\section{MR Görüntüleme ve Dental Alaşımlar}

Dental alaşımlar yıllardır farklı element kompozisyonlarından üretilmişlerdir. Bu alaşımların içeriğinde altın, palladyum, gümüş, nikel ve kobalt ile birlikte titanyum ve diğer elementlerde kullanılmaktadır. ${ }^{18}$ Günümüzde bu elementlerden yaygın olarak titanyum ve alaşımları kullanılmaktadır ve bu alaşımların biyolojik uyumlarının mükemmel olması, dirençlerinin yüksek olması, korozyon direncinin iyi olması protetik restorasyonlarda kullanım oranlarını yükseltmiştir. ${ }^{19}$ Titanyum ve alaşımlarının ferromanyetik olmadığı ${ }^{20}$ veya çok düşük oranlarda paramanyetik olduğu ${ }^{21,22}$ aynı zamanda elektromanyetik olarak minimum etkileşimde olduğu belirtilmiştir. ${ }^{21}$

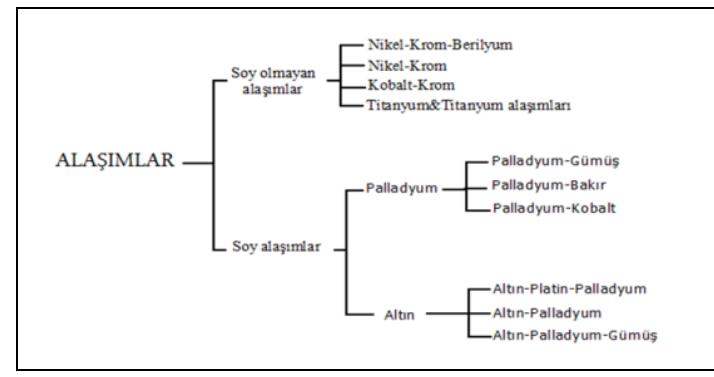

Şekil 2. Sabit protetik restorasyonlarda kullanılan alaşımların sınıflandırıması ${ }^{23}$ 
Dental alaşımların manyetik alandan etkilenmeleri bileşimlerinde bulunan elementlerin kimyasal kompozisyonuna bağlıdır. ${ }^{1}$ Diş hekimliğinde metal ve alaşımları geniş bir oranda ve yaygın olarak kullanılmaktadır. 1984 yılında ADA tarafından diş hekimliğinde kullanılan alaşımlar, içeriğindeki altın ve diğer elementlere göre yüksek soy, soy olan ve soy olmayan alaşım grubu şeklinde sınıflandırılmıştır. ${ }^{18}$

MR görüntüleme esnasında güçlü bir manyetik alan oluştuğu için ortamda ferromanyetik özellikte metallerin bulunması MR görüntüleme cihazının mıknatısları tarafından etkilenmelerine ve hareketlenmelerine neden olabilir. Bu yüzden hastalarda kalp pili, kalp kapakçık protezleri, serebral anevrizma klipleri ve vücutta bulunan ferromanyetik özellikteki protezler varsa MR görüntüleme esnasında metallerin hareket edebilme potansiyellerinden ötürü hastalar açısından güvenli olmayabilir. ${ }^{12,24}$

Dental materyaller manyetik yatkınlıklarına göre 3 şekilde sınıflandırılmışlardır. Manyetik alanda mıknatıslar tarafından güçlü bir şekilde çekime uğrayan materyaller ferromanyetik metaller olarak adlandırılırlar. ${ }^{2,25}$ Bu metaller manyetik alana sahip cisim ortamdan uzaklaştırıldığında, kazandığı manyetik özellik devam etmektedir ve bu metallere örnek olarak krom oksit, kobalt, demir, nikel, yitriyum vb. verilebilir. ${ }^{2}$ Ferromanyetik metaller Curie sıcaklığı denen kritik sıcaklık derecesini geçtiği zaman kalıcı mıknatıslanma özelliğini kaybeder ve paramanyetik duruma geçerler. ${ }^{2,25}$

Paramanyetik olarak adlandırılan metaller ise belirli bir manyetik alan altında zayıf bir çekim etkisi gösterirler ve bu manyetik alan ortadan kalktığında manyetik özelliklerini kaybederler. Bu metal grubuna örnek olarak magnezyum, platin, alüminyum vb. verilebilir. $^{2}$

Diamanyetik metallerde ise manyetik alan altında kendisini etkileyen cisim tarafından ters yönde itilirler ve manyetik olarak bu itme ve çekme birbirini dengelediğinden dolayı net manyetiklik de 0 olmaktadır. Manyetik alana yerleştirildiklerinde bile manyetik özellik göstermeyen bu metallere örnek olarak Çinko, Bakır, Gümüş, Altın vb. verilebilir. ${ }^{2}$

\section{MR Görüntülemenin Avantaj ve Dezavantajları}

Bu görüntüleme yönteminin başlıca avantajları; İyonize radyasyon kullanılmamasından dolayı radyasyonun zararlı etkilerine maruz kalınmamasi $^{1,26,27}$
- Görüntülerin yüksek kontrast rezolüsyonuna sahip olması ${ }^{26}$

- Yumuşak doku hastalıklarının teşhisinde çok etkili bir görüntüleme yöntemi olması ${ }^{1,26,27}$

- Bu görüntüleme yönteminde kullanılan kontrast maddelerin alerjik reaksiyon oluşturma riskinin, diğer görüntüleme yöntemlerinden daha düşük olması $^{27}$

Başlıca dezavantajları;

- Uzun çalışma süresinin olması ve gürültülü olması $^{26,27}$

- Hastaların görüntü alımı esnasında stabilitelerinin sağlanamaması $^{26}$

- Vücutta bulunan metalik objelerin, protezlerin ve biyomedikal aygıtların manyetik alandan etkilenerek hastaya zarar verebilmesi ${ }^{26,27}$

- Metalik objelerin manyetik alanı etkilemelerinden dolayı görüntülerde artifaktların oluşabilmesi ${ }^{28,29}$

\section{MR Görüntülemenin Dental Alaşımlara Etkilerì}

Dental hastalıkların teşhis ve tedavisi amacıyla çeşitli görüntüleme yöntemleri kullanılmaktadır. Bu görüntüleme yöntemlerinin birçoğu X-ray tabanlı görüntüleme yöntemlerinden oluşmaktadır. Bu yöntemlerin iyonize radyasyon içermesi ve buna bağlı intrakranial meningiom oluşumunda artış, ${ }^{30}$ pulpal, periapikal ve periodontal dokuların incelenmesinde yetersizliklere neden olması alternatif olarak MR görüntülemenin kullanımını ortaya çıkarmıştır. ${ }^{16}$

MR görüntülemenin baş-boyun bölgesinde kullanımı ve ağızda bulunan alaşımların bu görüntülemeye etkilerini araştırmak için birçok çalışma gerçekleştirilmiştir. MR incelemesi amacıyla gerçekleştirilen in vitro çalışmada; 15 ve 30 dakika MR görüntüleme uygulanan $\mathrm{Ni}-\mathrm{Cr}$ alaşımının Vickers sertliğinin uygulama süresi arttıkça sertlik derecelerinin azaldığını göstermiştir. Bu azalmaya sebep olarak da MR görüntülemenin iyon hareketlenmesini arttırdığını ve bunun sonucunda ısının yükselmesinin sebep olabileceği belirtilmiştir. $^{31}$

$\mathrm{Ni}-\mathrm{Cr}$, Co-Cr ve $\mathrm{ZrO}_{2}$ altyapılı restorasyonların MR görüntüleme öncesi ve sonrası sıcaklık ve ısı değişimleri ile manyetik alan etkileşimlerinin incelendiği invitro çalışmada, bir sıcaklık artışının olduğu ancak bu sıcaklık değişiminin yüksek miktarda olmadığı $(<1.4$ $\mathrm{C}^{0}$ ) ve herhangi bir risk teşkil edici manyetik hareketlenmenin olmadığı bildirilmiştir. ${ }^{32}$ MR görüntülemenin altın, gümüş, platin, palladyum ve bakır gibi alaşım- 
ların kompozisyonlarını içeren sabit köprü ve full ark köprü restorasyonlarının MR görüntüleme boyunca sıcaklık değişimlerinin incelendiği in-vitro çalışmada, restorasyonlarda sıcaklık değerlerinin arttığı bildirilmiştir ve köprü restorasyonlarında en yüksek sıcaklık artışı $1,80 \mathrm{C}^{\mathrm{O}}$ iken full ark restorasyonlardaki sıcaklık artışı $1,59 \mathrm{C}^{\mathrm{O}}$ bulunmuştur. $^{33}$

Dental amalgamın içeriğinde bulunan materyallerin MR görüntüleme sonrası manyetik alan ile etkileşiminin mikrosızıntıya etkilerinin incelendiği çalışmalarda gerçekleştirilmiştir. Araştırmalarda MR görüntülemenin mikrosızıntıyı etkilediği ${ }^{34}$ ve kontrol grubu ile kıyaslandığında mikrosızıntının arttığı bildirilmiştir. ${ }^{35}$ Ayrıca MR görüntülemenin Civa salınımına etkilerinin incelendiği klinik çalışmada, kontrol grubu ile kıyaslandığında MR görüntülemenin Civa salınımını arttırdığı bildirilmiştir. $^{36}$

Diş hekimliğinde kullanılan materyallerin MR görüntülemeleri esnasında davranışlarını incelemek amacıyla birçok çalışma gerçekleştirilmiş olup bu çalışmalar ağırlıklı olarak manyetik alan etkileşimleri, ISI artışı, hareketlenmeler ve radyolojik görüntüler üzerinde distorsiyon oluşturmaları ile ilgili çalışmalar olmuştur. Titanyum ve alaşımları içeren dental implantların 1.5T ve 3T MR cihazlarında ISı artışını inceleyen in vitro çalışmada, maksimum 0,4 C $\mathrm{C}^{0}$ lik bir ISı artışına sebep olduğu bildirilmiştir. ${ }^{22}$ Titanyum implantların 1.5T MR görüntüleme cihazında manyetik alan etkileşimlerinin incelendiği çalışmada herhangi bir hareketlenmenin görülmediği bildirilmiştir. ${ }^{37}$ Metalik dental materyallerin manyetik duyarlııkları ile ilgili yapılan bir in vitro çalışmada, Titanyum alaşımlarının manyetik duyarlılıklarının $\mathrm{Ni}-\mathrm{Cr}$ ve $\mathrm{Co}-\mathrm{Cr}$ alaşımlara göre daha az olduğu bildirilmiştir. $^{29}$

Ortodontik braketlerin ve $\mathrm{Ni}$-Ti, Paslanmaz çelik tellerin MR görüntülemesi sonucu ISı artışını ve Manyetik alan etkileşimini inceleyen araştırmada; ISı artışının aşırı derecelerde olmadığı $\left(<3.04 \mathrm{C}^{0}\right)$ ve manyetik alan etkileşimin kullanılan materyale göre değiştiği belirtilmiştir. Braketlerde çok düşük düzeyde manyetik etkileşim olduğu ve herhangi bir hareket gözlenmediği, Ni-Ti ve paslanmaz çelik tellerin manyetik alan etkileşimlerinin ve hareketlerinin hastalar için risk oluşturabileceği bildirilmiştir. ${ }^{38}$

Manyetik özelliğe sahip dental materyallerin ağız içi restorasyonlarında kullanılmaları MR görüntülemede risk teşkil etmektedir. Manyetik tutuculu protezlerin kullanılması MR görüntülemelerinde protezlerin güçlü manyetik alandan etkilenmeleri sonucunda hareketlenmelerine ve kayıplarına yol açabilmektedir. ${ }^{2}$ MR görüntüleme işlemi sırasında ağızda bulunan ve soy olmayan alaşımlar ile birlikte yüksek oranda Nikel içeren (\% 82) üst santral dişlere ait döküm post ve kronların işlem esnasında manyetik etkileşimden etkilendikleri ve nerdeyse dişleri yerinden çıkaracak şekilde hareketlendiği ve görüntüleme işleminin durdurulduğu literatürde rapor edilmiştir. ${ }^{39}$

Çeşitli metalik dental materyallerinin 3T ve 7T MR görüntüleme cihazları ile hareketlenme açılarının ve sıcaklık değişimlerinin incelendiği araştırmada; 7T MR görüntüleme cihazında hareketlenme açılarının daha fazla olduğu ve bu hareketlenmelerin özellikle $\mathrm{Co}-\mathrm{Cr}$ ve Ni-Cr alaşımlı full kronlarda görüldüğü, ayrıca dental implant ve abutmentlarda minimal hareketlenme açılarının olduğu ve manyetik ataçmanlarda ise hareketlenme açılarının yüksek olduğu bildirilmiştir. ${ }^{40}$

\section{SONUÇ}

MR görüntülemesi baş boyun bölgesini ilgilendiren özellikle yumuşak dokuların görüntülemesinde yaygın kullanılan bir görüntüleme tekniğidir. Bu görüntüleme tekniği kullanılırken hastanın vücudunda bulunan herhangi bir metalik objenin manyetik alandan etkilenmesi sonucu görülebilecek herhangi bir hareketlenme hastanın yaşamını tehdit edebilmektedir. MR görüntülemesi istenilecek tüm hastaların vücudunda bulunan metalik objeler yönünden detaylı bir anamnezinin alınması, ilgili objelerin manyetik etkileşimleri, ısınmaları yönünden değerlendirilmeleri ve hastanın oluşabilecek komplikasyonlar hakkında bilgilendirilmesi gerekmektedir.

Tahir Karaman, ORCID ID: 0000-0002-3764-637X

Bekir Eşer, ORCID ID: 0000-0002-1280-1257

Sedat Güven, ORCID ID: 0000-0002-2739-2281

Tuba Talo Yıldırım, ORCID ID: 0000-0002-7577-5703

\section{KAYNAKLAR}

1. Hubálková $H$, Serna $P$, Linetskiy I, Dostálová Tj. Dental alloys and magnetic resonance imaging. Int Den J 2006;56:135-41.

2. Mathew $\mathrm{CA}$, Maller $\mathrm{S}$. Interactions between magnetic resonance imaging and dental material. Jl Pharmacy Bioallied Sci 2013;5:113. 
3. Park J, Song $H$, Roh $H$, Kim $Y$, Lee J. Correlation between clinical diagnosis based on RDC/TMD and MRI findings of TMJ internal derangement. Int J Oral Maxillofac Surg 2012;41:103-8.

4. Matsuzaki $\mathrm{H}$, Katase $\mathrm{N}$, Hara M, Asaumi J-I, Yanagi $\mathrm{Y}$, Unetsubo $\mathrm{T}$, et al. Ameloblastic carcinoma: a case report with radiological features of computed tomography and magnetic resonance imaging and positron emission tomography. Oral Surg Oral Med Oral Pathol Oral Radiol Endod 2011;112:e40-7.

5. Espeland MA, Bryan RN, Goveas JS, Robinson JG, Siddiqui MS, Liu $S$, et al. Influence of type 2 diabetes on brain volumes and changes in brain volumes results from the women's health initiative magnetic resonance imaging studies. Diabetes care 2013;36:90-7.

6. Hargreaves BA, Worters PW, Pauly KB, Pauly JM, Koch KM, Gold GE. Metal-induced artifacts in MRI. American Journal of Roentgenology 2011;197:54755.

7. Labrousse M, Hossu G, Calmon G, Chays A, Felblinger $\mathrm{J}$, Braun $M$. In vivo characterization of the vestibulo-cochlear nerve motion by MRI. NeuroImage 2012;59:943-9.

8. Drzezga A, Barthel $H$, Minoshima S, Sabri $O$. Potential clinical applications of PET/MR imaging in neurodegenerative diseases. Journal of Nuclear Medicine 2014;55:47S-55S.

9. Geva T. Magnetic resonance imaging: historical perspective. Journal of Cardiovascular Magnetic Resonance 2006;8:573-80.

10. Brown MA, and Richard C. Semelka. MRI: basic principles and applications, Third Edition. John Wiley \& Sons 2003 p.1-19

11. Shafiei F, Honda E, Takahashi H, Sasaki T. Artifacts from dental casting alloys in magnetic resonance imaging. Journal of dental research 2003;82:602-6.

12. Shah N, Bansal N, Logani A. Recent advances in imaging technologies in dentistry. World J Radiol 2014;6:794-807.

13. Boeddinghaus $R$, Whyte $A$. Current concepts in maxillofacial imaging. European journal of radiology 2008;66:396-418.

14. Tymofiyeva O, Rottner K, Jakob P, Richter E-J, Proff $P$. Three-dimensional localization of impacted teeth using magnetic resonance imaging. Clinical Oral Investigations 2010;14:169-76.
15. Kress B, Buhl Y, Anders L, Stippich C, Palm F, Bähren W, et al. Quantitative analysis of MRI signal intensity as a tool for evaluating tooth pulp vitality. Dentomaxillofacial Radiology 2004;33:2414

16. Dragăn OC, Fărcășanu AȘ, Câmpian RS, Turcu RVF. Human Tooth and Root Canal Morphology Reconstruction Using Magnetic Resonance Imaging. Clujul Medical 2016;89:137-42

17. Tymofiyeva O, Rottner K, Gareis D, Boldt J, Schmid F, Lopez $M$, et al. In vivo MRI-based dental impression using an intraoral $\mathrm{RF}$ receiver coil. Concepts in Magnetic Resonance Part B: Magnetic Resonance Engineering 2008;33:244-51.

18. Wataha JC. Alloys for prosthodontic restorations. The Journal of Prosthetic Dentistry 2002;87:35163.

19. Uzun İh, Bayindir F. Dental Uygulamalarda Titanyum ve Özellikleri. Atatürk Üniv Diş Hek Fak Derg 2010;3:213-20.

20. Levine GN, Gomes AS, Arai AE, Bluemke DA, Flamm SD, Kanal E, et al. Safety of Magnetic Resonance Imaging in Patients With Cardiovascular Devices An American Heart Association Scientific Statement From the Committee on Diagnostic and Interventional Cardiac Catheterization, Council on Clinical Cardiology, and the Council on Cardiovascular Radiology and Intervention: Endorsed by the American College of Cardiology Foundation, the North American Society for Cardiac Imaging, and the Society for Cardiovascular Magnetic Resonance. Circulation 2007;116:2878-91.

21. Titanium Alloy Guide. RMI Titanium company An RTI internationals Metals, Inc Company 2000:1-45.

22. Ideta T, Yamazaki M, Kudou S, Higashida M, Mori $S$, Kaneda $T$, et al. Investigation of radio frequency heating of dental implants made of titanium in 1.5 tesla and 3.0 tesla magnetic resonance procedure: measurement of the temperature by using tissueequivalent phantom. Nihon Hoshasen Gijutsu Gakkai zasshi 2013;69:521-8.

23. O'Brien WJ. Dental materials and their selection, 4 Ed. Quintessence: 2008. p. 202-11

24. Gray CF, Redpath TW, Smith FW, Staff RT. Advanced imaging: magnetic resonance imaging in implant dentistry. Clinical oral implants research 2003;14:18-27. 
25. Goldman A. Handbook of modern ferromagnetic materials: Springer Science \& Business Media; 2012.p. 1-32

26. Herek D, Karabulut N. Manyetik Rezonans Görüntüleme. TTD Toraks Cerrahisi Bülteni 2010;1:214-22.

27. Kwong RY, Yucel EK. Computed tomography scan and magnetic resonance imaging. Circulation 2003;108:e104-6.

28. Zhuo J, Gullapalli RP. MR Artifacts, Safety, and Quality Control 1. Radiographics 2006;26:275-97.

29. Starčuková J, Starčuk Z, Hubálková H, Linetskiy I. Magnetic susceptibility and electrical conductivity of metallic dental materials and their impact on MR imaging artifacts. dental materials 2008;24:71523.

30. Longstreth W, Phillips LE, Drangsholt M, Koepsell TD, Custer BS, Gehrels JA, et al. Dental X-rays and the risk of intracranial meningioma. Cancer 2004;100:1026-34.

31. El-Bediwi AB, El-Fallal A, Saker S, Özcan M. Effect of non-ionizing radio frequency signals of magnetic resonance imaging on physical properties of dental alloys and metal-ceramic adhesion. J Adhes Dent 2014;16:407-13.

32. Ayyıldız S, Kamburoğlu K, Sipahi C, Murat S, Görgülü $S$, Pişkin B. Radiofrequency heating and magnetic field interactions of fixed partial dentures during 3-tesla magnetic resonance imaging. Oral surgery, oral medicine, oral pathology and oral radiology 2013;116:640-7.

33. Hasegawa M, Miyata K, Abe $Y$, Ishigami $T$. Radiofrequency heating of metallic dental devices during 3.0 T MRI. Dentomaxillofacial Radiology 2013;42:20120234.

34. Shahidi S, Bronoosh P, Alavi A, Zamiri B, Sadeghi $A$, Bagheri $M$, et al. Effect of magnetic resonance imaging on microleakage of amalgam restorations: an in vitro study. Dentomaxillofacial Radiology 2009;38:470-4.

35. Yilmaz S, Misirlioğlu M. The effect of $3 \mathrm{~T}$ MRI on microleakage of amalgam restorations. Dentomaxillofacial Radiology 2013;42:20130072.

36. Mortazavi S, Neghab M, Anoosheh S, Bahaeddini N, Mortazavi G, Neghab P, et al. High-field MRI and mercury release from dental amalgam fillings. The international journal of occupational and environmental medicine 2014;5:101-5.
37. Devge C, Tjellström A, Nellström H. Magnetic resonance imaging in patients with dental implants: a clinical report. International Journal of Oral \& Maxillofacial Implants 1997;12.

38. Görgülü S, Ayyıldız S, Kamburoğlu K, Gökçe $S$, Ozen T. Effect of orthodontic brackets and different wires on radiofrequency heating and magnetic field interactions during 3-T MRI. Dentomaxillofacial Radiology 2014;43:20130356.

39. Sinkiewicz D. MRI scan hazard. British dental journal 2013;214:376.

40. Oriso K, Kobayashi T, Sasaki M, Uwano I, Kihara H, Kondo $\mathrm{H}$. Impact of the Static and Radiofrequency Magnetic Fields Produced by a 7T MR Imager on Metallic Dental Materials. Magnetic Resonance in Medical Sciences 2016;15:26-33.

\section{Yazışma Adresi}

Dr. Öğr. Üyesi Tahir Karaman

Fırat Üniversitesi Diş Hekimliği Fakültesi

Protetik Diş Tedavisi A.D.

23000/Elazığ, Türkiye

Tel: +905375679559

E-mail: tkaraman@firat.edu.tr 